\title{
MANUEL FRAIJÓ Y JAVIER SÁDABA, DOS FILOSOFÍAS DE LA RELIGIÓN EN DIÁLOGO. UNA APROXIMACIÓN DOCUMENTAL
}

\author{
MANUEL FRAIJÓ AND JAVIER SÁDABA, TWO \\ PHILOSOPHIES OF RELIGION IN DIALOGUE. A \\ DOCUMENTARY APPROACH
}

\author{
MARÍA DEL Olmo* \\ Universidad de Alicante
}

Resumen: Este artículo tiene por objetivo ofrecer una primera aproximación al estudio comparativo de la Filosofía de la religión de dos filósofos españoles contemporáneos que han dedicado una amplia parte de su reflexión a esta disciplina: Manuel Fraijó y Javier Sádaba. La primera parte ofrece aquellos datos biográficos que los vinculan, la segunda parte traza las convergencias y divergencias entre ambos pensamientos y la tercera parte corresponde al estudio bibliográfico de sus respectivas obras estableciendo una posible clasificación para las mismas.

Palabras clave: Filosofía de la religión española, Filosofía española contemporánea.

AвSTRACT: This article aims to provide an initial approach to a comparative study of the philosophy of religion of two contemporary Spanish philosophers who have devoted a large part of their reflection to this discipline: Manuel Fraijó and Javier Sádaba. The first part provides biographical information that links the two philosophers, the second part outlines the similarities and differences between their thinking, and the third part corresponds to the bibliographic study of their works by establishing a possible classification for them.

KEYwORDS: Spanish philosophy of religion, contemporary Spanish philosophy

\footnotetext{
"maria.delolmo@ua.es
} 


\section{Introducción biográfica}

Dos referentes importantísimos para el estudio de la Filosofía de la Religión en España son los filósofos Manuel Fraijó y Javier Sádaba. Es así primeramente, como ya he señalado en otros trabajos ${ }^{1}$, por una cuestión anecdótica: desde la cátedra de Ética de Javier Sádaba en la Universidad Autónoma de Madrid se imparte por primera vez esta disciplina y la cátedra de Filosofía de la religión de Manuel Fraijó en la UNED es la primera en constituirse como tal en nuestro país ${ }^{2}$. En segundo lugar, y más importante, porque su dedicación y su producción bibliográfica sobre esta materia son intensas y amplísimas. Por ello, la primera aproximación que quiero hacer a ambos pensadores de manera conjunta se centra en la recopilación de esta vasta producción intelectual, objeto del presente estudio.

Sin embargo, me parece pertinente comenzar este trabajo ofreciendo unos mínimos datos que expliquen los nexos de unión entre ambos filósofos y que permitan entender el diálogo que en próximos estudios pretendo establecer entre ellos. $^{3}$

Si partimos de la información biográfica que es conocida sobre cada uno de ellos debo empezar por señalar que Javier Sádaba nació en Portugalete, Bilbao, en 1940 y Manuel Fraijó en Guadalcázar, Córdoba, en 1941, por tanto, son coetáneos. La fecha y el lugar de nacimiento no son datos triviales en el caso de sus respectivas biografías porque la España de la década de los cuarenta en la que ambos nacen y crecen es la España del nacional catolicismo franquista, un escenario que estableció un contexto de fuertes y condicionantes coordenadas vitales que no podemos obviar. En los dos casos, su infancia y primera juventud está ligada a la orden religiosa de los jesuitas. Javier Sádaba estudió en el colegio

\footnotetext{
${ }^{1}$ OLMO IBÁÑEZ, María de (2014) 1. El universo Sádaba, Javier Sádaba ante el espejo o el otro Sádaba: una aproximación documental. Alicante: Universidad, Taller digital.

OLMO IBÁÑEZ, María del. Javier Sádaba y la filosofía de la religión: ¿una cuestión existencial? En Eikasia no 64, mayo 2015. Pág 113-135

${ }^{2}$ Manuel Fraijó contó en la conferencia que impartió en el IX Encuentro Eleusino en Ávila (1 noviembre 2014) que hubo un intento frustrado por parte de Ortega de atraer a Unamuno a una cátedra de Filosofía de la Religión en Madrid. https://www.youtube.com/ watch?v=Avx52nuqhGc

${ }^{3}$ Dicho trabajo ya se ha publicado: OLMO IBÁÑEZ, María del (2017). Manuel Fraijó y Javier Sádaba. Un diálogo entre dos filósofos de la religión. Madrid: Tecnos.
} 
religioso de Las Arenas de Bilbao y después pasó cuatro años en el Seminario de Comillas regido por los jesuitas. El vínculo de Manuel Fraijó es más intenso ya que fue sacerdote jesuita, aunque después se secularizó. Este dato me interesa principalmente porque considero que revela un característico y riguroso proceso de formación.

Los dos se licenciaron en Teología, Javier Sádaba por la Universidad Gregoriana de Roma y Manuel Fraijó por la Universidad de Tubinga. Sádaba es también licenciado en Filosofía y Fraijó en Filosofía y Ciencias de la Educación, los dos son doctores en Filosofía, y Fraijó también en Teología. Ya sus tesis doctorales estuvieron ligadas a la religión, la tesis de Javier Sádaba tuvo que ver, por supuesto, con Wittgenstein, pero aplicado al lenguaje religioso: "El concepto de filosofía en Ludwig Wittgenstein y su aplicación al lenguaje religioso" y la tesis de Fraijó estudió al gran teólogo protestante W. Pannenberg: "El sentido de la historia. Introducción al pensamiento de W. Pannnenberg." En los dos casos han sido fieles toda su vida intelectual a estos orígenes.

Otro rasgo destacado de su preparación académica es que ambos completaron su formación en Italia, Sádaba en Roma y Fraijó en Nápoles, y después en Alemania. Los dos estudiaron en Tubinga, aunque Manuel Fraijó pasó primero por Münster. Tubinga es la ciudad de las cátedras de los grandes teólogos alemanes protestantes y católicos y, en el tiempo de sus estancias, coincidieron con Joseph Ratzinger o Hans Küng, personaje fundamental en la vida de Manuel Fraijó, quizás como Ludwig Wittgenstein lo ha sido para Javier Sádaba.

Es imprescindible concluir los datos biográficos sobre ellos haciendo alusión a la relación de amistad que les une desde hace mucho tiempo, Javier Sádaba y Manuel Fraijó son dos buenos amigos.

\section{Dos modos de hacer filosofía de la religión}

La breve introducción biográfica, en la que se han puesto de manifiesto los paralelismos que se pueden establecer entre las vidas de ambos pensadores, sirve también para explicar el interés inicial que el hecho religioso ha podido tener en la reflexión de ambos filósofos. Sin embargo, mi pretensión de poner a dialogar a ambos pensamientos proviene de la percepción clara de que cada uno de ellos representa una perspectiva distinta en el enfoque de sus respectivos estudios de 
la Filosofía de la religión. Es desde ahí, desde dónde reviste especial interés establecer un diálogo entre ellos.

Si nos preguntamos cuáles son esos enfoques distintos que adoptan estos dos filósofos de la religión, en un mínimo esbozo de la cuestión, se puede afirmar que Javier Sádaba, que se declara agnóstico, ha tenido como primera pretensión y como motor fundamental de su trabajo sobre la disciplina, la desvinculación radical de esta de la teología: "No es sencillo distinguir la religión de la teología. Por otro lado, es fundamental tener en cuenta tal distinción pues, en caso contrario, se viene abajo cualquier intento por obtener alguna luz en el laberinto de la religión". Al mismo tiempo ha defendido la desvinculación de cualquier religión positiva. Sádaba encuentra serias dificultades para afrontar la enseñanza de la Filosofía de la religión profesando un credo, por eso se decanta a favor del profesor aconfesional. Al referirse a la condición del docente de esta materia afirma: "no debería ser el creyente [...] No es intelectualmente libre para poder opinar sobre la religión, especialmente sobre la que él mismo práctica. De ahí que más que enseñar religión lo que hará es adoctrinar." ${ }^{4}$

Para Sádaba una de las causas principales del estancamiento de la Filosofía de la religión es precisamente su incapacidad para desvincularse del todo de la Teología:

La Filosofía de la Religión no goza de tanta salud, sino que, rodeada de sospechas, trata, con dificultad, de remontar el vuelo. Las causas de esta desproporción son varias. Una de tales causas es que huele aún demasiado a teología. Sería como un retoño de ésta, el último producto secularizado de nuestra religión.

En el mismo artículo explica la radical diferencia entre ambas disciplinas: "la Teología Filosófica no es Filosofía de la Religión. Porque ésta, lo veremos enseguida, es una investigación que cartografía las creencias religiosas. Y, cosa

${ }^{4}$ SÁDABA, Javier (1989). Lecciones de filosofía de la religión. Mondadori. Pág. 39. Es fundamental el capítulo que Sádaba dedica a "Las dificultades pedagógicas de una filosofía de la religión”. 
decisiva, es trasversal a todas las creencias, más allá de la que a nosotros nos envuelve." 5

Manuel Fraijó, adopta otro ángulo de aproximación a la Filosofía de la religión. Él funde en su pensamiento filosofía y teología, quizás siguiendo la reflexión de Unamuno que recoge en la introducción a su libro "Fragmentos de esperanza" al explicar su propio método de trabajo:

Es posible que haya una mezcla impura entre filosofía y religión. Pero pienso como Unamuno, que la separación no es fácil ni, tal vez, deseable. Así veía las cosas el rector de Salamanca: «Filosofía y religión son enemigas entre sí, y por ser enemigas se necesitan una a otra. Ni hay religión sin alguna base filosófica, ni filosofía sin raíces religiosas; cada una vive de su contraria. La historia de la filosofía es, en rigor, una historia de la religión» ${ }^{6}$

L. Martínez Gómez, historiador de la filosofía, en su reseña precisamente de este mismo libro de Fraijó explica bien su modo de hacer filosofía de la religión: "la actitud del autor, aquí rigurosamente filósofo de la religión, no puro filósofo ni teólogo, aunque bebe y vive de los dos campos o fuentes, es de una vital reflexión, que apellidaríamos radical y al mismo tiempo humilde y abierta, talante dolorosamente dubitativo, pero con resquicios (fragmentos) para la esperanza, algo en la línea de E. Bloch"7. Además, Fraijó no se declara agnóstico, creo que más bien coincide con lo que suele repetir que escuchó decir al teólogo jesuita Rhaner en una conferencia: "no soy creyente a tiempo completo". Esta distinción entre las posiciones de Sádaba y Fraijó, me parece sustancial. Con respecto a la condición del docente de la filosofía de la religión en la conferencia que dio sobre la materia en el Curso "La Filosofía de Gustavo Bueno"8 Fraijó reconoció sus dudas sobre la confesionalidad como posibilidad o como impedimento.

Creo que el conjunto de diferencias entre ambos pensadores conforma la radical diferencia, la divergencia esencial que existe entre ellos. Sádaba, desde su

\footnotetext{
${ }^{5}$ SÁDABA, Javier. Por qué interesa a un agnóstico la Filosofía de la Religión. En Bajo palabra. Revista de filosofía, 2009, no 4, p. 21-32.

${ }^{6}$ FRAIJÓ, Manuel (1992). Fragmentos de esperanza. Estella: Verbo Divino.

${ }^{7}$ MARTÍNEZ GÓMEZ, L. Reseńa del libro "Fragmentos de esperanza" de Manuel Fraijó. En Pensamiento 202(1996). Pág. 167-168

${ }^{8}$ Curso La Filosofía de Gustavo Bueno. Cuarta Mesa: Filosofía de la Religión y Teología. Gustavo Bueno, Manuel Fraijó. Madrid, Colegio de Doctores y Licenciados de Madrid, 5 de marzo de 1999.
} 
agnosticismo, ha detenido las preguntas, defiende con su querido Wittgenstein la realidad del hecho religioso en sentido amplio, pero comparte con Hume su asombro ante la capacidad del ser humano de lanzarse inconsciente, intrépido, insaciable, atemorizado o asombrado, al Más Allá. Desde la filosofía habla Sádaba y estos dos filósofos son su principal fuente de inspiración en este campo. Describe y construye con objetividad científica la filosofía de la religión y la sistematiza en su obra "Lecciones de Filosofía de la religión", sin dejar de contemplar, antropológicamente y compadecido, al ser humano enfrentado a las grandes preguntas de la existencia. Ante el misterio del mundo opta por el silencio y defiende que no se puede dar un paso más lejos de lo que conocemos. Por otro lado es imprescindible señalar que desde su decisión perenne de comprometer su palabra de filósofo, Javier Sádaba es muy crítico con los credos religiosos y, especialmente, con los monoteístas y sus fundamentalismos. Al mismo tiempo, no oculta sus simpatías por el taoísmo y, sobre todo, por el jainismo, la religión "atea", desde esa perspectiva abarcadora que adopta sobre el hecho religioso en sentido amplio.

Al pensamiento de Fraijó, quizás, le atraviesa la duda, las preguntas están latentes, aunque no tenga respuesta y en la búsqueda de respuestas convoca a los grandes teólogos alemanes protestantes y católicos: Barth, Otto, Rhaner, Pannenberg, Küng, etc. Sin embargo, se atreve también a escuchar a pensadores ateos como E. Bloch y su gran obra "El principio de esperanza", en su intento por hermanar filosofía y teología para abordar la cuestión. Pienso que Manuel Fraijó construye filosofía de la religión desde su personal búsqueda, por eso su pensamiento parte del sentido de la historia, con una preocupación primordial por la compensación necesaria a las víctimas de esta, relacionada con la cuestión del mal. Avanza, centrándose en el cristianismo y la figura de Jesús de Nazaret, importantísima en su pensamiento, y culmina con su enorme interés por el diálogo interreligioso, por el establecimiento de puentes entre los diversos credos, defendiendo la existencia de verdades parciales y no de absolutos.

Una vez establecidas estas mínimas premisas, que he considerado imprescindibles para poder entender el sentido de este artículo, paso a presentar la recopilación bibliográfica y documental, que revela bien los rasgos expuestos sobre sus respectivos pensamientos y que constituye la fuente documental básica de otros estudios míos sobre ambos pensadores. 


\section{Aproximación bibliográfica y documental a dos filósofos de la religión: Manuel Fraijó y Javier Sádaba}

La metodología de este apartado ha sido, en primer lugar, la recopilación de la bibliografía convencional de ambos filósofos: monografías, colaboraciones en monografías y artículos, tratando de ofrecer los enlaces de aquellos que estén en red. Y en segundo lugar, otros documentos en línea como conferencias, cursos, etc. Considero que en el siglo XXI ningún estudio bibliográfico riguroso puede obviar el ámbito digital. Una vez recopilado todo el material lo he clasificado atendiendo a los diversos temas sobre la religión que a cada uno de los dos pensadores le ha preocupado, ya que he estimado que dicha clasificación ofrece una información muy relevante sobre la orientación de sus reflexiones. Desde ese punto de vista se pueden establecer convergencias y divergencias sustantivas entre ellos. Ambos coinciden en el interés por los siguientes temas:

- Filosofía de la religión.

- Cristianismo: aunque los trabajos de Sádaba se circunscriben más al ámbito del catolicismo.

- Otras religiones: Fraijó añade a este tema su interés por el diálogo interreligioso quizás influido por su maestro Hans Küng.

- El problema del mal.

- La cuestión de Dios.

- Religión y Ética.

- Espiritualidad.

Sus divergencias dan lugar a intereses particulares de cada uno de ellos:

- Manuel Fraijó: El sentido de la historia, Jesús de Nazaret, Teología

- Javier Sádaba: Wittgenstein y la religión, la muerte.

Por último, en ambos casos hay un apartado para otros temas. 


\subsection{Manuel Fraijó}

\subsubsection{Cristianismo}

\section{Libros y colaboraciones en libros}

Frajó́, Manuel. El futuro del cristianismo. Madrid: Ediciones SM, 1985

Frajó, Manuel; MASIÁ CLAVEL, Juan. Cristianismo e Ilustración: homenaje al Profesor José Gómez Caffarena en su setenta cumpleańos. Madrid: Universidad Pontificia de Comillas, 1995

Frajó, Manuel. El cristianismo. Una aproximación. Madrid: Trotta, 1997

Frajó, Manuel. Introducción al pensamiento teológico de W. Pannenberg. En A. Vargas-Machuca (ed.), Jesucristo en la historia y en la fe. Salamanca: Sígueme, 1977. Pág. 327-337.

Fraijó, Manuel. Resurrección. En FlORISTÁN, C., TAMAYO, J.J. (eds.) Conceptos fundamentales del cristianismo. Madrid; Trotta, 1993. Pág. 1196-1215; Año

Fraijó, Manuel. Exegese und Dogma. Eine notwendige Versöhnung. En H. HÄRING, H; KUSCHEL, K.J. (eds) Neue Horizonte des Glausbens und Denkens. Munich: Piper, 1993. Pág. 250-270

Fraijó, Manuel. La modernidad: luces y sombras. En Cristianismo y modernidad. Madrid: Nueva Utopía, 1993. Pág. 17-42

Fraijó, Manuel. Teología de la liberación: elogio y preguntas. En GIMBERNAT, J.A.; GÓMEZ, C. (eds.): La pasión por la libertad. Homenaje a Ignacio Ellacuría. Estella: Verbo Divino, 1994

Fraijó, Manuel. Evocación y recuerdos. En MASIÁ ClAVEL, J. (ed.). Cristianismo e Ilustración: homenaje al Profesor José Gómez Caffarena en su setenta cumpleaños. Madrid: Upco, 1995. Pág. 19-38

Fraijó, Manuel. Fragmentos de esperança. Notas para uma filosofía da religiāo. Sāo Paulo (Brasil): Paulinas, 1999

Aguayo, Francisco. Las cofradias de la Villa de Guadalcázar durante la Modernidad. FRAIJÓ, Manuel (Pról.). Córdoba: Diputación, 2002. Pág.11-16

Fraijó, Manuel. La libertad en la tradición judeocristiana y en la tradición de la Modernidad: un diálogo crítico. En Dios, Trinidad y la libertad del hombre, (4º Congreso Trinitario, Granada, noviembre 2002). Córdoba: Caja Sur, 2003 
Fraijó, Manuel. Del Jesús histórico al Cristo de la fe: horizontes de futuro. En 25 años de teología: Balance y perspectivas. Madrid: Cátedra Chaminade, Fundación Santa María, 2006. Pág.141-161

Frajoó, Manuel. Del catolicismo intimista al cristianismo heterodoxo. En Aranguren. Filosofía en la vida y vida en la filosofía. Madrid: Ed. Sociedad Estatal de Conmemoraciones Culturales/Instituto de Filosofía del CSIC, 2009. Pág.133-161

Frajó, Manuel (pról.) "Del catolicismo al cristianismo. Reflexión sobre el itinerario religioso de J. L. L. Aranguren”. LÓPEZ ARANGUREN, J.L. La crisis del catolicismo. Colección Grandes Pensadores Españoles. Barcelona: Planeta, 2011.Pág. 9-43

Fraijó, Manuel. La resurrección como problema fundamental de la teología cristiana. En Reflexiones teológicas. David G. López Galvis (ed.), Ed. Bonaventuriana (Serie Teológica no 16), 2013. Pág. 37-74 ISBN: 978-958-8422-71-8

\section{Artículos}

Frajó, Manuel. El sacramento de la confirmación: su problemática y significado. En Diálogo; No 78, 1976. Pág. 40-46

Fraijó, Manuel. Carta abierta a Hans Küng [en línea]. En "El País”. 29-12-79. Disponible en: http://elpais.com/diario/1979/12/29/sociedad/315270001_850215.html

Fraijó, Manuel. Hans Küng en conflicto con Roma. Método teológico y contenidos doctrinales. En Iglesia Viva; No 85, 1980. Pág. 65-87.

Fraijó, Manuel. Los derechos de los pobres como lugar teológico. En Pastoral Popular; No: 1, 1980. Pág. 27-33

Fraijó, Manuel. La resurrección, sentido para una humanidad irredenta. En Sal Terrae; No 2, 1980. Pág. 201-212.

Fraijó, Manuel. Utopía y esperanza cristiana. Revista de Occidente; No: 33-34, 1984. Pág. 37-48

Fraijó, Manuel. El Dios encarnado. En Laicado; No: 68, 1985. Pág. 65-77

Frajó, Manuel. Historiografía de los orígenes del cristianismo I. En Memoria Académica del Instituto "Fe y Secularidad", 1986-1987. Pág. 85-90

Fraijó, Manuel. Historiografía de los orígenes del cristianismo II. En Memoria Académica del Instituto "Fe y Secularidad", 1987-1988. Pág. 102-108

Fraijó, Manuel. Los teólogos que Roma desea. En Éxodo; No 5, 1989. Pág. 58-64

Fraijó, Manuel. Hans Küng: tiempo y contratiempo. En Éxodo; No: 30, 1995. Pág. 15 ss. 
Frajó, Manuel. Demasiado honor para el papa Woytyla [en línea]. En Revista Internacional de Filosofía Política; No: 7, 1996. Pág.199-207. Disponible en: http://e-spacio.uned.es/fez/eserv.php?pid=bibliuned:filopoli-1996-7-B1DCC181D531-9537-228C-0129A7497081\&dsID=demasiado_honor.pdf

Frajó́, Manuel. Una iglesia en el mundo y para el mundo. En Éxodo; No: 33, 1996. Pág. 26-30

Frajó, Manuel. Cristianismo y disidencia. En Entre la disidencia y la tolerancia (AA. VV.); No: 33, 1996. Pág. 87-111

Frajó, Manuel. ¿Quién teme a la razón? Cristianismo y argumentación. En Sal Terrae, 1997 (julio - agosto). Pág. 587-597

Frajó, Manuel. Del catolicismo al cristianismo. Reflexión sobre el itinerario religioso de José L. López Aranguren [en línea]. En Isegoría; No: 15, 1997. Pág.157-180. Disponible en: file://C:/Users/User/Downloads/173-173-1-PB.pdf

Frajó, Manuel. Incoherencias en el cristianismo. En Crislam Revista de Diálogo cristiano-musulmán, Madrid, 1999. Pág.163-175

Frajó, Manuel. El cristianismo y sus relaciones con la sociedad. En Córdoba: Aula FeCultura de ETEA, Memoria del Curso Académico 2005-2006. Pág. 26-48.

Frajjó, Manuel. El cristianismo. En Diálogo Mediterráneo, no 4, 2006. Pág. 18-20

Fraijó, Manuel. Le christianisme. En Dialogue Mèditerranèe, no 41, 2006. Pág. 25

Frajoó, Manuel. Resurrección. En “Teología en 100 palabras”, El Ciervo, marzo 2006. Pág. 23

Fraijó, Manuel. Esperanza y trascendencia en Pedro Laín. En INTERSTICIOS, filosofía, arte, religión, México, año 15, núm. 32, ene-jun. 2010. Pág. 129-147

Frajó́, Manuel. La mirada crítica y necesaria de Hans Küng [en línea]. En El País, Madrid, 25-1-2011. Disponible en: http://elpais.com/diario/2011/01/25/opinion/1295910012_850215.html

Fraijó, Manuel. Hans Küng: trayectoria y obra. Laudatio en el Solemne Acto de Investidura como Doctor honoris causa del profesor Hans Küng [en línea], UNED, Madrid, 27 de enero de 2011 Disponible en: file://C:/Users/User/ Downloads/3348-3347-1-PB.pdf

Fraijó, Manuel. La mirada crítica y necesaria de Hans Küng. En Éxodo. Rehenes del capitalismo, Madrid, no 107, febrero 2011.

Frajó, Manuel. Hans Küng: pensar la religión. En Utopía y praxis latinoamericana. Revista Internacional de Filosofía Iberoamericana y Teoría Social. Venezuela, no 2 (Portadilla), enero-marzo 2011. 
Fraijó, Manuel. Esperanza y trascendencia en Pedro Laín [en línea]. En COMPRENDRE. Revista catalana de filosofía, Universitat Ramón Llull, Barcelona, 2011, vol. 12/1 Pág. 49-65. Disponible en: file://C:/Users/User/Downloads/269322-366147-1SM.pdf

Fraijó, Manuel. ¿Qué hacer con la Semana Santa? En Firmas invitadas. Guadalajara: Fundación Siglo Futuro, abril 2012.

Frajó, Manuel. In memoriam, “José Gómez Caffarena, vivencia de esperanza” [en línea]. En El País, 20 de febrero, 2013. Disponible en: http://cultura.elpais.com/ cultura/2013/02/19/actualidad/1361301064_014533.html

Frajó́, Manuel. Elogio de una renuncia [en línea]. En El País, 12 de febrero, 2013. Disponible en: http://elpais.com/elpais/2013/02/11/opinion/1360611396_869602. html

Fraijó, Manuel. Nuevo Papa, viejas urgencias [en línea]. El País, 16 de marzo, 2013. Disponible en: http://elpais.com/elpais/2013/03/15/opinion/1363369768_898882. html

Fraijó, Manuel. In memoriam: José Gómez Caffarena. En Isegoría, no 48, enerojunio, 2013. Pág. 351-357, ISSN. 1130-2097

Fraijó, Manuel. De la metafísica a la filosofía de la religión. Itinerario intelectual de José Gómez Caffarena. En Razón y fe, no 1377-1378, julio-agosto 2013. Pág. 39-50. ISSN 0034-0235

Fraijó, Manuel. La Iglesia que quiere el papa Francisco [en línea]. En El País, 3 de septiembre, 2013. Disponible en: http://elpais.com/elpais/2013/08/21/opinion/1377094606_056378.html

Fraijó, Manuel. Wolfhart Pannenberg, clave de la teología protestante [en línea]. El Pais, 20 de septiembre, 2014. Disponible en: http://sociedad.elpais.com/sociedad/2014/09/19/actualidad/1411156547_052837.html

Fraijó, Manuel. Wolfhart Pannenberg, clave de la teología protestante [en línea]. El País, 20 de septiembre, 2014. Disponible en: http://sociedad.elpais.com/sociedad/2014/09/19/actualidad/1411156547_052837.html

Frajó, Manuel. La serena certeza del deber cumplido [en línea]. El País, 24 de diciembre, 2014. Disponible en: http://elpais.com/elpais/2014/12/18/opinion/1418930590_976646.html

\section{Documentos audiovisuales en línea}

Hans KüNG: hacia una teología universal [en línea]. UNED, Televisión, 17-06-2011 Disponible en: https:/www.youtube.com/watch?v=dB9OXZSC3yk 
Manuel Frajó y Wolfhart Pannenberg [en línea]. Radio UNED. Serie: Filosofía en Radio 3. Disponible en: https://www.youtube.com/watch?v=P1O1KK3whN4

\subsubsection{Sentido de la Historia}

\section{Libros y colaboraciones en libros}

Frajó, Manuel. Das Sprechen von Gott bei W. Pannenberg. Tesis Doctoral. Tübingen, 1976.

Fraijó, Manuel. El sentido de la historia. Introducción al pensamiento de W. Pannenberg. Madrid: Cristiandad, 1986

\section{Artículos}

Frajó, Manuel. Ernst Bloch o la utopía del reino. En Razón y Fe; No: 956-957, 1977. Pág. 904ss

Frajó, Manuel. Interpretación existencial y universal de la historia: de Bultmann a Pannenberg. En Proyección No 100, Instituto "Fe y Secularidad"1977-78. Pág. 43-54

Fraijó, Manuel. Sobre la racionalidad de la historia. En Memoria Académica del Instituto "Fe y Secularidad", 1979-80. Pág. 69 ss.

Fraijó, Manuel. Ética y sentido de la historia: Actas del II encuentro hispano-mexicano de Filosofía Moral y Politica. En Instituto de Filosofía, CSIC, Madrid, 1988 Pág.368-378

Frajó, Manuel. El sentido de la historia. Respuesta de Hegel a los enigmas del mundo. En Memoria Académica del Instituto "Fe y Secularidad", 1989-1990. Pág. 91-108

Frajoó, Manuel. ¿Esperanza después de la guerra del golfo? Reflexión filosófico - teológica. En Éxodo; No 9, 1991. Pág.34-44

\subsubsection{Jesús de Nazaret}

\section{Libros y colaboraciones en libros}

Fraijó, Manuel. Jesús y los marginados. Utopía y esperanza cristiana. Madrid: Cristiandad, 1985

Fraijó, Manuel. AlEGRE, X., TORNOS, A. (eds.). La resurrección de Jesús desde la filosofía de la religión, La fe cristiana en la resurrección: XXI Foro sobre el Hecho Religioso, Madrid, 19-21 septiembre 1997. Santander: Sal Terrae, 1998. 
Fraijó, Manuel. La mujer en el Nuevo Testamento. En Mujeres y hombres en la formación del pensamiento occidental. Actas de las VII Jornadas de Investigación interdisciplinaria Vol. I. Madrid: Universidad Autónoma de Madrid; 1989. Pág.153-169.

Fraijó, Manuel. Jesús de Nazaret y la fe en Dios. En Dios como problema en la cultura contemporánea. Bilbao: Editorial Ega, 1989. Pág.155-179

Fraijó, Manuel. Jesús y la libertad. En Jesús de Nazaret. Perspectivas. Madrid PPC, 2003. Pág. 103-124

\section{Artículos}

Fraijó, Manuel. La “pretensión” de Jesús: una escala de valores nueva e incómoda. En Sal Terrae; No 4, 1976. Pág. 295-304.

Fraijó, Manuel. Jesús y los marginados. Prolegómenos para una teología de la marginación. En Razón y Fe; No 978-979, 1979. Pág. 4-18.

Fraijó, Manuel. La Comunión y la diferencia en el proyecto utópico de Jesús. En Corintios XIII; No 11-12, 1979. Pág. 215-240

Fraijó, Manuel. Jesús de Nazaret, esperanza para los débiles. En Actualidad Catequética; No 97-98, 1980. Pág. 39-57

Fraijó, Manuel. Jesús ante la violencia. En Misión Abierta; No 3, 1982. Pág. 97-110

Fraijó, Manuel. Jesús frente al sistema dominante de su época. En Razón y Fe; No 1088, 1989. Pág. 626-638

Fraijó, Manuel. Jesús de Nazaret y otros disidentes. En Éxodo; No 0, 1989. Pág. 34-40

Fraijó, Manuel. Jesús: compromiso con la sociedad. En Biblia y Fe, enero-abril 2000. Pág. 57-98

\subsubsection{Otras religiones, ecumenismo, diálogo entre religiones}

\section{Libros y colaboraciones en libros}

Fraijó, Manuel. (ed.). Fundamentalismo y violencia. Córdoba: UNED, 2004

Fraijó, Manuel. ¿Religión sin Dios en suelo monoteísta? En Pensar la religión. Madrid: Fundación Juan March, 2000. Pág. 71-91

Moreno Pampliega, Javier. Muchas religiones, una verdad ¿Podemos creer aún? FRAIJÓ, Manuel (pról.). Erasmus Ediciones, 2011. Pág. 9-11. 


\section{Artículos}

Fraijó, Manuel. El monoteísmo entre la universalidad y el particularismo (o la elección)”. En Iglesia Viva; No 158, 1992. Pág.137-192

Fraijó, Manuel. Entre la convicción y la tolerancia. El Caso de Jesús de Nazaret. En Utopia; No: 13 (marzo) 1995. Pág. 19-23

Frajó, Manuel. Foi Jesús um tolerante? En Jornal Fraternizar; No: 81 (junio) 1995. Pág. 14-17

Fraijó, Manuel. Fuera de la Iglesia no hay salvación. En Exodo; No: 142, 1998. Pág. 33-39

Frajó, Manuel. Hans Küng: el reto del ecumenismo y de una ética universal. En $E l$ Ciervo; No: Julio-agosto, 1998. Pág. 5-71998

Fraijó, Manuel. Las religiones y la paz mundial. En Insular (Menorca), 24 de marzo de 2001

Fraijó, Manuel. ¿Cuándo le saldrá al islam su Lutero? En El Periódico de Gijón, 23-42002

Fraijó, Manuel. Islam y fanatismo. En Diario Córdoba, 4 -4-2002

Fraijó, Manuel. El reto del islam [en línea] . En Eguzkilore. Cuaderno del Instituto Vasco de Criminología, no 18, 2004. Pág.135-145. Disponible en: http://www.ehu.eus/doc uments/1736829/2174326/10Fraijo.pdf

Frajó, Manuel. Siete despedidas del Foro sobre el Hecho Religioso. En El Ciervo, diciembre 2004. Pág. 23

Frajó, Manuel. Tolerancia frente a fanatismo [en línea]. En El País, 12-2-2005. Disponible en: http://elpais.com/diario/2005/02/12/babelia/1108167439_850215. html

Fraijó, Manuel. ¿Quién evangelizará a los evangelizadores? [en línea]. El País, 14-62012. Disponible en: http://sociedad.elpais.com/sociedad/2012/06/14/vidayartes/1339700089_442779.html

\section{Documentos audiovisuales en línea}

Fraijó, Manuel. Conferencia: La fe en el islam [en línea]. Almería. Centro Indalo Loyola. Disponible en: https://www.youtube.com/watch?v=zSLmUu60Jx8

Fraijó, Manuel. , Insua, Pedro. Mesa redonda: Multiculturalismo y diálogo entre religiones [en línea]. II Jornadas de Nódulo en Talavera. 7 -11-2014. Disponible en:

https://www.youtube.com/watch?v=FlhnNhtk6UI 
Fraijó, Manuel. Conferencia: Dialogo de religiones [en línea]. Almería, Centro Indalo Loyola, 2014. Disponible en:

https://www.youtube.com/watch?v=bOmFQ-yhFmg

\subsubsection{El problema del mal}

\section{Libros y colaboraciones en libros}

Fraijó, Manuel. Satán en horas bajas. Santander: Sal Terrae, 1993

Fraijó, Manuel; CASTILLA DEL PINO, Carlos (ed.). ¿Envidia de Dios? Hacia una teoría de Satán. Madrid: Ed. La Envidia, Alianza Universidad, 1994

Fraijó, Manuel. Dios, el maly otros ensayos. Madrid, Trotta, 2004

Fraijó, Manuel. El cristianismo ante el enigma del mal. Carta a un amigo increyente. En ARAMAYO, Roberto R. ÁLVAREZ, J. Francisco (eds.) Disenso e incertidumbre. Un homenaje a Javier Muguerza. Madrid-México: Plaza y Valdés Ediciones, 2006. Pág. 87-137

Fraijó, Manuel. Interrogantes cristianos sobre el enigma del mal. En Los rostros del mal. Madrid: Instituto Universitario de Ciencias de las Religiones, UCM, ediciones Khaf, 2010. Pág. $257-298$

Fraijó, Manuel. Dios y el mal. En BARRADO, Pedro, ESTRADA, Juan Antonio [et al] Misterio del mal y fe cristiana. Valencia: Fundación Chaminade. Tirant Humanidades, 2012. Pág. 241-260.

Frajó, Manuel. Dios: ¿problema o misterio? En BERMEJO, D. (ed.), ¿Dios a la vista? Madrid: Dykinson, 2013. Pág. 149-172.

Fraijó, Manuel. Dios y el mal. En GARCÍA NAVARRO, J. J., RODRÍGUEZ GARCÍA, R., CALLEJO HERNANZ, Ma J. (eds.) De la libertad del mundo. Homenaje a Juan Manuel Navarro Cordón, ed. Escolar y Mayo, Madrid 2014. Pág. 455-466. ISBN: 978-84-1602-26-3.

\section{Artículos}

Frajó́, Manuel. El mal: así lo vive el cristianismo. En Iglesia viva; No: 175/176, 1994. Pág.79-112

Fraijó, Manuel. Satán, abandonado por los teólogos. En Misión, Uruguay; No: Marzo, 1997. Pág.13-20

Fraijó, Manuel. El mal. Así lo vive el cristianismo. En Praxis. Seminario Ibérico de Filosofía, Centro de Filosofía da Universidade de Lisboa, 2000. Pág.189-219 
Fraijó, Manuel. Dios y el enigma del mal [en línea]. En El País, 5-2-2005. Disponible en: http://elpais.com/diario/2005/02/05/sociedad/1107558007_850215.html

\subsubsection{Filosofía de la religión}

\section{Libros y colaboraciones en libros}

Fraijó, Manuel. Fragmentos de esperanza. Estella: Verbo Divino, 1992

Fraijó, Manuel. Filosofía de la religión. Estudios y textos. Madrid: Trotta, 1994

Fraijó, Manuel. A vueltas con la religión. Estella: Verbo Divino, 1998

Frajó́, Manuel. E. Bloch: religión como utopía. En VEGA, L., RADA, E., MÁS, S. (Eds.). Del pensar y su memoria (Ensayos en homenaje al profesor Emilio Lledó). Madrid: UNED, 2001. Pág. 497-508

\section{Artículos}

Frajuó, Manuel. ¿Religión sin Dios? XXI Conferencias Aranguren [en línea]. En Isegoría 47, 2012. Pág. 381-419. ISSN 1130-2097. Disponible en: http://isegoria. revistas.csic.es/index.php/isegoria/article/viewFile/787/786

\section{Documentos audiovisuales en línea}

HOMENAJE a MANUEL FRAIJÓ: pensando la religión [en línea]. Radio UNED Serie: Filosofía en Radio 3. 16-1- 2014. Disponible en: https://www.youtube.com/ watch?v=2nEqHrYF3kM

Gustavo Bueno y MANUel FRAijó: Filosofía de la Religión y Teología [en línea]. Curso de Gustavo Bueno. 5-3-1999. Disponible en:

https://www.youtube.com/watch?v=2Lu5EcEz6X8

NEGRO SOBRE BLANCO. "RELIGIÓN" [en línea]. Congreso de Filósofos 2003 sobre "Dios y la religión”, mesa redonda, moderada por Fernando Sánchez Dragó que fue emitida en el programa de televisión "Negro sobre Blanco", 17-5-2003. Intervinieron: Gustavo Bueno, José Antonio Marina y Manuel Fraijó. Disponible en:

https:/www.youtube.com/watch?v=sN-FIBwQamY 


\subsubsection{La cuestión de Dios}

\section{Libros y colaboraciones en libros}

Frajó, Manuel. Realidad de Dios y drama del hombre. Madrid: Fundación Santa María, 1985

Fraijó, Manuel; GARCÍA HERRERO, J. (ed.). A la búsqueda de Dios. Madrid: Ediciones San Pablo, 1995.

Fraijó, Manuel. Dios, el maly otros ensayos. Madrid, Trotta, 2004

Fraijó, Manuel. Dios: ¿Problema o misterio? En Ciudad de los hombres, ciudad de Dios. Homenaje a Alfonso Álvarez Bolado, S.J. Madrid: Universidad Pontificia de Comillas, 1999. Pág. 265-288.

Frajó́, Manuel. A la caza de la verificación. El estatuto epistemológico de las afirmaciones sobre Dios. En GÓMEZ CAFFARENA, J., MARDONES, J.M. (eds.) La tradición analitica. Materiales para una filosofia de la religión II, Barcelona; Anthropos, 1992. Pág. 81-107

Fraijó, Manuel. Acceso a Dios desde la filosofía: cinco parábolas. En GARCÍA HERRERO, J. (ed.): A la búsqueda de Dios. Madrid: San Pablo, 1995

Otto, R. Lo santo. Fraijó, Manuel. Pról. Barcelona: Círculo de Lectores, 2000

Fraijó, Manuel. Religión y Dios. En ¿Hay lugar para Dios hoy? Madrid: PPC, 2005

Fraijó, Manuel. Dos filósofos ante Dios. En La crisis de Dios hoy. Madrid: Khaf, 2013. Pág. 137-173. ISBN: 978-84-15995-00-5.

\section{Documentos audiovisuales en línea}

Conferencia: ¿Religión sin Dios? [en línea]. IX Encuentro Eleusino. Ávila, -11- 2014. Disponible en: https://www.youtube.com/watch?v=Avx52nuqhGc

\subsubsection{Religión y ética}

\section{Libros y colaboraciones en libros}

Frajó, Manuel. Religión y ética en conflicto. De la sobriedad ética a la esperanza religiosa. En MONTIEL, L., GARCÍA, M. (edit.), Pensar el final: la eutanasia. Éticas en conflicto. Madrid, Editorial Complutense, 2007, Colección Pensar nuestro tiempo. Pág. 171-193. 


\section{Artículos}

Fraijó, Manuel. De la sobriedad ética a la esperanza religiosa [en línea]. En Isegoría; No: 10, 1994 Pág. 30 Disponible en: http://isegoria.revistas.csic.es/index.php/isegoria/article/view/271/271

Frajó, Manuel. ¿Vivir sin ética, vivir sin religión? [en línea]. En El País, 8 de febrero, 2014. Disponible en: http://elpais.com/elpais/2014/01/31/opinion/1391181818_441642.html

\subsubsection{Teología}

\section{Libros y colaboraciones en libros}

Fraijó, Manuel. Teología y vida eterna: la vida y el más allá. En AA.VV., Teología de la vida: comienzo y final. Madrid: PPC, 2009. Pág. 270-308

\section{Artículos}

Frajó, Manuel. Semana Internacional de Teología. En Estudios Eclesiásticos; No 202, 1977. Pág. 397-400

Fraijó, Manuel. Una alternativa teológica "desde abajo. En Memoria Académica del Instituto "Fe y Secularidad”, 1979-80. Pág. 27-33

Frajó, Manuel. Reflexión teológica sobre el cambio. En Misión Abierta; No: 1, 1984. Pág.116-124

Fraijó, Manuel. La teología entre la ciencia y la utopía. Presupuestos para el carácter científico de la teología. En Proyección; No: 138, 1985. Pág. 181-195

\subsubsection{Espiritualidad}

\section{Artículos}

Frajó́, Manuel. És posible una espiritualitat laica més enllà de les religions? [en línea] En COMPRENDRE. Revista catalana de filosofía, Universitat Ramón Llull, Barcelona 2009, Pág. 5-15. Disponible en: file://C:/Users/User/Downloads/Dialnet-EsPossibleUnaEspiritualidadLaicaMesEnllaDeLesRelig-3075879.pdf

Fraijó, Manuel. ¿Es posible una espiritualidad laica más allá de las religiones? En INTERSTICIOS, filosofía, arte, religión, México, julio-dic. 2009, ańo 14, no 31. Pág. $45-56$ 


\subsubsection{Otros temas}

\section{Libros y colaboraciones en libros}

Fraijó, Manuel. Belleza y salvación. Madrid: Instituto Fe y Secularidad, 1996

\section{Artículos}

Frajoó, Manuel. Espiritualidad y política. En Exodo. Espiritualidady politica en tiempos de turbación, Madrid, no 115, octubre 2012. Pág. 14-25.

Fraijó, Manuel. Perplejidades y preguntas. En Misión, Montevideo (Uruguay); No: Mayo, 1999. Pág. 23-30

Fraijó, Manuel. Autobiografía intelectual. En SAN MARTíN, Javier, SÁNCHEZ BERNAL, Juan José (eds.) Pensando la religión. Homenaje a Manuel Fraijó. Madrid: Trotta, 2013. ISBN: 978-84-9879-442-7, 2013. Pág. 29-50.

Fraijó, Manuel. Conversación con Javier San Martín y Juan José Sánchez. En SAN MARTÍN, Javier, SÁNCHEZ BERNAL, Juan José (eds.) Pensando la religión. Homenaje a Manuel Fraijó. Madrid: Trotta, 2013. Pág. 51-71

\subsection{Javier Sádaba}

\subsubsection{Filosofía de la religión}

\section{Libros y colaboraciones en libros}

SÁdABA, JaVIER. Qué es un sistema de creencias. Salamanca: Editorial Mañana, 1978.

SÁDABA, JAVIER. Lenguaje religioso y filosofía analitica: (del sinsentido a una teoría de la sociedad). Barcelona: Fundación Juan March, 1977.

Sádaba, Javier. Filosofía, lógica y religión. Salamanca: Sígueme, 1978.

SÁdABA, JaVIER. Lecciones de filosofía de la religión. Madrid: Mondadori, 1989.

SÁdaba, Javier. De Dios a la nada. Las creencias religiosas. Madrid: Espasa-Calpe, 2006

Diccionario de Filosofía Contemporánea, Miguel Ángel Quintanilla (dir.). Salamanca: Editorial Sígueme, 1976. (La voz Filosofía de la religión es de Sádaba)

Hume, David. Historia natural de la religión: Diálogos sobre la religión natural. Pról. Javier Sádaba. Salamanca: Sígueme, 1974. 
SÁdABA, Javier. La Religión y sus formas. En SÁDABA, Javier. Saber vivir. Madrid: Libertarias, 1984. Pág. 95 y ss.

SÁDABA, Javier. La filosofía de la religión en la universidad española. En Estudiar la religión: materiales para una filosofía de la religión III. Consejo Superior de Investigaciones Científicas, CSIC, 1993. Pág. 141-151.

SÁdAba, Javier. Filosofía de la religión y sentido de la vida. En Religión. Madrid: Trotta, 1993. Págs. 211-222.

SÁdAba, Javier. Filosofía de la religión en Wittgenstein. En Filosofía de la religión. M. Fraijó (ed.) Madrid: Editorial Trotta, 1994.

SÁdABA, JAVIER. Voces del Más Allá. ¿La biología absorbe la religión? En SÁDABA, Javier. La vida en nuestras manos. Madrid: Ediciones B, 2001

SÁdABA, Javier. El futuro de la Religión. ¿Vuelve Dios? Su impacto político. En ¿Dios a la vista? BERMEJO, Diego (ed.). Madrid: Dykinson, 2014.

SÁdABA, JAvier. Por qué interesa a un agnóstico la filosofía de la religión. En SAN MARTÍN, J, SÁNCHEZ, J.J. Pensando la religión: Homenaje a Manuel Fraijó. Madrid: Trotta, 2014.

\section{Artículos}

Sádaba, Javier. La religión y sus formas. En El Viejo topo, extra no 5, 1979. Pág. 45-48. ISSN: 0210-2706

SÁdABA, Javier. ¿Es posible una Filosofía de la Religión?, En Enrahonar. Quaderns de Filosofia, Universidad Autónoma de Barcelona, no 2, 2o semestre de 1981. Pág. 5 11. ISSN: 0211-402X

SÁdAba, Javier. El retorno de la religión en la posmodernidad. En Pliegos de estraza, Madrid, abril 1984. Pág. 5-14.

SÁdABA, Javier. Entre exigencia de conocimiento y libertad de razón (Lecciones sobre "Filosofía de la Religión" de Hegel). En La Gazeta del Libro, Madrid, no 17, 2a quincena de febrero de 1985. Pág. 22.

SÁdABA, Javier. Una perspectiva desde la filosofía de la religión. Javier Sádaba; Alfonso Moraleja (entrev.), Lorenzo Estaún de Torres (entrev.) En Cuaderno gris, 1987, págs. 10-12. ISSN: 0213-6872

SÁdABA, Javier. La filosofía de la religión en la universidad española. En Estudiar la religión: materiales para una filosofía de la religión III. Consejo Superior de Investigaciones Científicas, CSIC, 1993. Pág. 141-151.

SÁdABA, Javier. La Religión como materia. El Mundo 26/06/1996 
SÁdaba, Javier. Religión: filosofías, creyentes y milenaristas. En Pensamiento de los Confines, no 8, Primer Semestre de 2000, Facultad de Ciencias Sociales, Buenos Aires, Argentina. Pág. 50-54.

SÁdaba, Javier. Mi idea de religión. En Herria 2000. Eliza, Bilbao, no 179, 2002. Pág. 28.

SÁdaba, Javier. Aproximaciones filosóficas a la religión desde España. En Debate: filósofos españoles ante la religión Iglesia viva: revista de pensamiento cristiano, No. 221, 2005, págs. 91-116. [En línea] http://www.iglesiaviva.org/221/221-31-DEBATE. pdf

SÁDABA, JAVIER. ¿Es posible la filosofía de la religión? [en línea] En Enrahonar: quaderns de filosofia, 2006, no 2. Pág. 5-11. ISSN: 0211-402X. Disponible en: http://ddd. uab.cat/pub/enrahonar/0211402Xn2/0211402Xn2p5.pdf

SÁdAba, Javier. Por qué interesa a un agnóstico la Filosofía de la Religión [en línea]. Bajo palabra. Revista de filosofía, 2009, no 4. Pág. 21-32. ISSN: 1576-3935. Disponible en: file://C:/Users/User/Downloads/Dialnet-PorQueInteresaAUnAgnosticoLaFilosofiaDeLaReligion-3175156\%20(4).pdf

\section{Documentos audiovisuales en línea}

SÁdABA, JAVIER. ¿Por qué es éticamente importante la Filosofía de la Religión? [en línea] Universidad Nacional Autónoma de México, 14-17 de noviembre, 2011. Repositorio de la Facultad de Filosofia y Letras. UNAM. Disponible en: http://ru.ffyl.unam. mx:8080/jspui/handle/10391/3942

SÁdaba, Javier. El futuro de la Religión ¿Vuelve Dios? [en línea] Univ. Politécnica Valencia. Alcoy 23 de noviembre de 2013. Disponible en:

https://www.youtube.com/watch?v=TH98ykg5kWo

\subsubsection{Cristianismo, catolicismo}

\section{Libros y colaboraciones en libros}

Miret Magdalena, Enrique; Sádaba, Javier. El catecismo de nuestros padres. Barcelona: Plaza y Janés, 1998.

SÁdaba, Javier. Dios y sus máscaras. Madrid: Temas de Hoy, 1993

SÁdABA, Javier. Catolicismo español y moralidad. En La influencia de la religión en la sociedad española. Madrid. Libertarias, 1994. 


\section{Artículos}

Sádaba, Javier. Jesuitismo de la praxis, En Hiperión, Madrid, no 3, 1978. Pág. 30 - 34.

Sádaba, Javier. Carne de hombre y carne de Dios. En Creación, Estética y Teoría de las Artes, Madrid, publicada por el Instituto de Estética y Teoría de las Artes, no 3, Mayo de 1991, pp. 18 - 23. ISSN. 1130-2186

Sádaba, Javier. Cristianoescepticismo con gramos de esperanza. En "El Mundo", La Esfera, 17-10-1992.

SÁdABa, Javier. “El cristianismo: una aproximación” de Manuel Fraijó. En "El Mundo”. La Esfera, 10-1-1998.

\section{Documentos audiovisuales en línea}

\section{LA CLAVE:}

$05 / 04 / 1985$

Católica España [en línea]

Disponible en: https://www.youtube.com/watch?v=1SKDZytWxt0

\subsubsection{Religión y ética}

\section{Libros y colaboraciones en libros}

SÁDABA, JAVIER. Moral y religión. En El futuro de la religión, (compilación de Gerardo Martínez Cristerna) México: Fundación Cultural Hombre y Mundo, 2006, Pág. 158-171.

SÁDABA, JAVIER. La religión como falsa garantía de la moral. El cristianismo, ficción y enseñanza. En SÁDABA, Javier: La vida buena. Barcelona: Península, 2009

\section{Artículos}

Sádaba, Javier. Religión sin ética [en línea]. El País 7-10-1983. Disponible en: http:// elpais.com/diario/1983/10/07/opinion/434329201_850215.html

SÁdABA, Javier. Las inmoralidades de la religión [en línea]. El País 16-6-1988. Disponible en: http://elpais.com/diario/1988/06/16/sociedad/582415202_850215.html 
SÁdaba, Javier. Wittgenstein, ética y religión. En: Cuaderno gris, No. 7-8, 1990, págs. 44-54. ISSN: 0213-6872

\subsubsection{Otras religiones}

\section{Libros y colaboraciones en libros}

SÁdaba, Javier. De Dios a la nada. Las creencias religiosas. Madrid: Espasa-Calpe, 2006

SÁDABA, Javier. El caso de dos religiones cristianismo y budismo. Oyendo a Oriente y a Occidente. En SÁDABA, Javier: La vida buena. Barcelona: Península, 2009

Moratiel, Virginia. Mirando de frente al Islam. Prólogo Javier Sádaba. Madrid: Xorki, 2013.

\section{Artículos}

SÁdAbA, Javier. Pobres y musulmanes El Mundo. 19/03/1997

SÁdAbA, Javier. Crítica general al fundamentalismo. En Ágora. Papeles de Filosofía, Universidad de Santiago de Compostela, Vol. 22, Número 2, 2003. Pág. 193-206. ISSN 2174-3347

\section{Documentos audiovisuales en línea}

\section{LAS NOCHES BLANCAS. TELEMADRID}

$23 / 2 / 2007$

Religiones [en línea].

Disponible en: https://www.youtube.com/watch?v=X2krkekxLy4

\subsubsection{Espiritualidad}

\section{Libros}

SÁDABA, JAVIER. El hombre espiritual: ética, moral y religión ante el nuevo milenio. Barcelona: Martínez Roca, 1999. 


\subsubsection{El problema del mal}

\section{Libros}

SÁdaba, Javier. La vida buena. Barcelona: Península, 2009.9

SÁdaba, Javier. No sufras más. Barcelona: Península, 2012 $2^{10}$

\section{Artículos}

SÁDABA, JAVIER. Incidencia del judaísmo en la problemática actual del mal. En El mal: irradiación y fascinación. Serbal, 1993. Pág. 224-229.

\subsubsection{Wittgentein y la religión}

\section{Libros y colaboraciones en libros}

SÁDABa, Javier. Filosofía de la religión en Wittgenstein. En Filosofía de la religión. M. Fraijó (ed.) Madrid: Editorial Trotta, 1994,

SÁDABA, Javier. Rigor moral y cobijo religioso en Wittgenstein. En Wittgenstein, 50 años después, I Congreso Hispano-Luso de Filosofía, (coordinadores Andoni Alonso y Carmen Galán. Mérida: Junta de Extremadura, Serie Estudios Portugueses 21, 2002, Pág. 253-266.

SÁdaba, Javier. Lo místico en Wittgenstein, En El filosofar hoy, (Oscar Nudler y Francisco Naishtat editores). Buenos Aires: Editorial Biblos, 2003. Pág. 49-58.

WitTGenstein, Ludwig; SÁDABA, Javier (trad. y prólogo). Observaciones a" La rama dorada" de Frazer. Tecnos, 2008.

\section{Artículos}

SÁDABA, Javier. Lo místico en Wittgenstein [en línea]. En Taula, quaderns de pensament, 1998, no 29-30. Pág. 57-64. Disponible en: https://books.google.es/books?h l=es\&lr=\&id=RJh7gLJ0tLgC\&oi=fnd\&pg=PA57\&dq=javier+S\%C3\%A1daba+y+

\footnotetext{
${ }^{9}$ El apartado: Los rivales del bienestar o felicidad: el sufrimiento y el mal. Pág. 99 y ss.

${ }^{10}$ Especialmente el capítulo 4. Las respuestas para superar el sinsentido de la vida. Pág. 55 y ss.
} 
religi\%C3\%B3n\&ots=E7TP29KEnk\&sig=OXWvPlAHWqHd1qmOgxCEyneQj $\mathrm{T} 4 \# \mathrm{v}=$ onepage \&q=javier\%20S\%C3\%A1 daba $\% 20 \mathrm{y} \% 20$ religi $\% \mathrm{C} 3 \% \mathrm{~B} 3 \mathrm{n} \& \mathrm{f}=$ false

\subsubsection{La cuestión de Dios}

\section{Artículos}

Sádaba, Javier. Hanson y el agnóstico [en línea], en Teorema, Valencia, 1976, vol. 6, no 3, 1976, pág. 435 - 454. ISSN: 0210-160. Disponible en: file://C:/Users/User/ Downloads/Dialnet-HansonYElAgnostico-2046514\%20(2).pdf

SÁdaba, Javier. El ateísmo en la vida cotidiana, En Revista de Occidente, Madrid, no 2, julio-septiembre 1980. Pág.39-52. ISSN: 0034-8635

SÁdABA, Javier. La fe de los incrédulos. En Herria 2000. Eliza, Bilbao no 33, abril 1981. Pág. 38-41.

Sádaba, Javier. Dios ante el fin de siglo. En Revista Nómadas [en línea] Madrid: Universidad Complutense, no 0, 2003. ISSN 1578-6730. Disponible en: http://pendientedemigracion.ucm.es/info/nomadas/0/jsadaba.htm

\section{Documentos audiovisuales en línea}

NEGRO SOBRE BLANCO. TVE 2

$01 / 04 / 2002$

La resurrección de Dios [en línea]

Disponible en: https://www.youtube.com/watch?v=nLMz4FnEgY0

\subsubsection{La muerte}

\section{Libros}

SÁdAba, Javier. Saber morir. Madrid: Libertarias/Prodhufi, 1991.

\section{Artículos}

SÁdABA, Javier. Vida y muerte. El Mundo 22/09/1994

SÁdABA, Javier. Fiestas y muertos. El Mundo. 01/11/1996 


\subsubsection{Otros temas}

\section{Artículos}

Sádaba, Javier. Religión y marginación. En El Viejo topo, no 27, diciembre 1978. ISSN: 0210-2706

De la política a la religión [en línea]. El País 2-1-1987. Disponible en:

http://elpais.com/diario/1987/01/02/opinion/536540410_850215.html

SÁdAba, Javier. Sobre la religión según Sánchez Ferlosio. En El Urogallo, Madrid, no 11, marzo 1987. Pág. 11-13. ISSN: 0049-5719

SÁdAba, Javier. La religión contra la burocracia. En Misión Abierta, Madrid, no 3, junio 1987. Pág.53-61. ISSN 1131-7477

Como bien puede deducirse, después de este recorrido bibliográfico, existen afinidades y discrepancias reflexivas, que afectan al planteamiento, pero también al contenido entre las obras de Manuel Fraijó y Javier Sádaba, en torno al amplio y controvertido ámbito de la Filosofía de la religión y las religiones. Creo que reviste un gran interés el estudio comparativo de la producción intelectual de ambos filósofos de la religión que este artículo inicia, ya que nos va a permitir confeccionar una cartografía bastante amplia y ajustada de ambos pensamientos y de lo que sobre esta disciplina se ha hecho en España en las últimas décadas.

Recibido: 12/09/2015

Aceptado: 19/10/2015

\section{@(9) $(0 \Theta$}

ENDOXA está bajo una licencia de Creative Commons Reconocimiento-NoComercial-SinObraDerivada 4.0 Internacional 